\title{
Peginterferon Alfa-2a Regimen
}

National Cancer Institute

\section{Source}

National Cancer Institute. Peginterferon Alfa-2a Regimen. NCI Thesaurus. Code

C160106.

A chemotherapy regimen consisting of peginterferon alfa- $2 a$ that may be used in the treatment of myeloproliferative neoplasms and systemic mastocytosis. 